\title{
Omuz sıkışma sendromunda güncel teknikler ve klinik sonuçları
}

\author{
Current techniques and clinical results in shoulder impingement syndrome
}

\author{
İsmail Türkmen, Fikret Berkan Anarat
}

\author{
T.C. Sağlık Bakanlığı, Göztepe Prof. Dr. Süleyman Yalçın Şehir Hastanesi, Ortopedi ve Travmatoloji Kliniği, İstanbul
}

Omuz sıkışma sendromu genellikle dejeneratif ve kronik zeminde karşımıza çıkar. Hastalar tipik olarak baş üstü işleri yaparken ortaya çıkan ve gece rahatsızlık vererek uyumasına engel olan omuz ağrısı ile başvurur. Tanı temel olarak anamnez ve fizik muayenedeki ilgili omuz testleriyle büyük oranda konur fakat uygun görüntüleme yöntemleriyle de desteklenir. Fizyoterapi, oral antienflamatuvar ilaçlar ve subakromial enjeksiyonlar sıklıkla uygulanan cerrahi dışı tedavi yöntemleridir. Hastanın bu tedavilere rağmen devam eden şikâyetleri olduğunda, açık ya da artroskopik uygulanan cerrahi yöntemler devreye girmektedir. Artroskopik subakromial dekompresyon ve debridman bu amaçla yapılan en sık cerrahilerden biridir. Prognoz için, cerrahi tedaviler hastanın ağrı, fonksiyon ve hayat kalitesini olumlu etkilemektedir. Fakat, omuz sıkışma sendromu hastalarında uygulanan cerrahi tedavinin, konservatif yöntemlere göre uzun dönem sonuçlar açısından üstünlüğü olmadığını gösteren orta kanıt düzeyinde yayınlar bulunmaktadır. Bu derlemede omuz sıkışma sendromunu, güncel tedavi seçeneklerini ve klinik sonuçları özetlenmiştir.

Anahtar sözcükler: omuz sıkışma sendromu; subakromial dekompresyon; prognoz
Most shoulder impingement is degenerative or chronic. Patients typically experience pain with overhead tasks during daily activities and discomfort at night. Diagnosis is led by history and relevant shoulder tests of physical examination, but it should be supported with proper imaging. Conservative measures such as physiotherapy, subacromial cortisone injection and oral anti-inflammatory medications are often initially applied for treatment. When symptoms persist, surgical intervention via open or arthroscopic means becomes a featured option. Arthroscopic subacromial decompression and debridement has become one of the most common orthopaedic procedures for this manner. For prognosis, surgery provides improvement in pain, function, and quality of life. However, there is moderate evidence that surgical treatment is not more effective than conservative treatment strategies for long term results of patients suffering from shoulder impingement syndrome. This review summarizes the current treatment options and clinical outcomes of shoulder impingement.

Key words: shoulder impingement syndrome; subacromial decompression; prognosis

sendromu (subacromial impingement syndrome, SAIS) ya da eksternal sıkışma olarak anılmakta ve hastalar tipik olarak kronik süreçte baş üstü hareketlerde ağrı ve gece ağrısı şikâyetleriyle başvurmaktadır. Omuz sıkışma ana başlığı içerisinde kabul edilen diğer bir alt başlık ise özellikle genç hastalarda tekrarlayan baş üstü spor travması ile ortaya çıkan glenohumeral instabilite ya da diğer bir isimle internal sıkışmadır.

\section{OMUZ SIKIŞMA SENDROMU}

\section{Anatomi}

Daha önceden omuz sıkışma sendromu kendi başına bir tanı olarak nitelendirilse de günümüzde bir yonundaki mekanik sıkışması olarak tanımlamıştır. ${ }^{[4]} \mathrm{Bu}$ tanım güncel yaklaşımda subakromial sıkışma 
grup semptom ve anatomik oluşumun birleşmesi olarak değerlendirilmektedir. ${ }^{[5]}$ Subakromial boşluğu sınırlandıran anatomik yapılar; anteriorda akromion ve korakoakromial ligaman, superiorda akromioklavikular eklem, inferiorda ise humerus başı ve tuberkulum majustur. Bu alan rotator manşet kaslarının hareket alanıdır ve akromionun şekli sıkışmaya sebep olan eksternal faktörlerin başında sayılmaktadır. Akromion, morfolojisine göre üç tipe ayrılmıştır: ${ }^{[6]}$ Tip 1-düz, Tip 2-anteriora eğimli, Tip 3-çengel/kanca tip.

Omzun abduksiyon, öne fleksiyon ve internal rotasyon hareketleri sırasında humerus başı superiora migrasyon göstermekte ve akromionun antero-inferior sınırına yaklaşmaktadır. ${ }^{[7]}$ Bu yakınlaşma normalde 1,0 ile $1,5 \mathrm{~cm}$ genişliğinde olan subakromial aralıkta daralmayı ifade eder. Hastanın ağrı şikâyetleri bu sıkışma sonrası humerus başının rotator manşet ve subakromial bursaya yaptığı bası ile iliş̧ilidir. Tekrarlayan sıkışma dejenerasyonu ve alanda kronik daralmayı beraberinde getirerek tendon enflamasyonu ile sonuçlanır. Neer, omuz sıkışmasını üç evre olarak tanımlamıştır. Evre 1'de, sıkışma sonrası birincil ödem ve hemoraji görülürken, Evre 2 fibrozis ve geri dönüşümsüz tendon değişiklikleri ile karakterizedir. Tendon rüptürü kronik ağrı ve uzayan fibrotik süreç olan Evre 3'ü ifade eder. ${ }^{[4,8]}$

\section{Anamnez ve Fizik Muayene}

İyi alınmış bir anamnez ve iyi uygulanan fizik muayene omuz sıkışma sendromu tanısında en önemli basamaktır. Hastanın şikâyeti genellikle baş üzeri hareketlerde ve o taraf üzerine yatma ile ortaya çıkan, akromiondan humerus ortasına doğru uzanan bir ağrıdır. Eklem hareket kısıtlılığı, hastanın uyumasına engel olan gece ağrısı da başvuru nedeni olabilir. Güç kaybı ve eklemdeki katılık ise ağrıya ikincil olarak gelişir. Şikâyetlerin başlangıcı birkaç hafta ya da ay önce olabilir ve genellikle başlatan bir olay ya da travma ifade edilmez. ${ }^{\left[{ }^{[9]}\right.}$ Hastanın şikâyetlerini artıran, rahatlatan ya da atak süreçleri, tekrarlayan travmaları ile gündelik baş üstü işlerindeki konforu ayrıntılı olarak sorgulanmalıdır. İstirahat, antienflamatuvar ilaç kullanımı ve buz uygulaması ile geçici rahatlama dönemleri ifade edilse de aktivite ile ağrının tekrarlaması ve kronik süreç ortaya konulmalıdır.

Fizik muayenede omzun inspeksiyonu, palpasyonu, pasif ve aktif eklem hareket açıklıkları ve spesifik stres testlerinin rolü vardır. Etkilenen tarafta abduksiyon ve/ veya eksternal rotasyon hareketlerinde güçsüzlük olabilir. Kas atrofisi göz ardı edilmemelidir. Korakoid çıkıntıda palpasyon ile hassasiyet genellikle görülür. Spesifik testler bu sendromun tanısında önemli rol oynamaktadır. Bu testler; Hawkins testi, Neer işareti, Jobe testi, ağrılı ark testidir. Teker teker incelendiğinde bu testler yüksek sensitiviteye fakat düşük spesifiteye sahiptir, ancak kombine olarak değerlendirilmeleri omuz sıkışma sendromu konusunda oldukça değerlidir.

Hawkins testi: Omuzda pasif olarak öne $90^{\circ}$ 'lik elevasyon sonrası maksimum iç rotasyonda ağrı varlığı sorgulanır..$^{[10]}$

Neer işareti: Skapula elle sabitlendikten sonra, omuz pasif olarak fleksiyona getirilir ve ağrı sorgulanır. ${ }^{[4]}$

Jobe testi: Omuz $90^{\circ}$ abduksiyondayken baş parmak aşağıyı gösterecek şekilde ön kol ve kol iç rotasyona getirilir ve ağrı sorgulanır.

Ağrılı ark testi: Omzun $70^{\circ}$ ile $120^{\circ}$ arasındaki abduksiyon hareketiyle ortaya çıkan ağıı sorgulanır.

$\mathrm{Bu}$ testlerin pozitif olması klinisyeni omuz sıkışma sendromuna yaklaştırırken, omuz instabilitesi ile ilgili testler olan sulkus işareti, anterior korkutma ve relokasyon testlerinin negatif olması da sıkışma sendromu tanısında değerlidir.

\section{Görüntüleme}

Anamnez ve fizik muayenenin omuz sıkışma sendromu tanısı için sensitivitesinin \%90'lara vardığını gösteren yayınlar bulunsa da görüntüleme tetkikleri bu hastalarda çoğunlukla diğer patolojileri dışlamak için gereklidir. ${ }^{[9]}$ Omzun standart görüntülemesi olan antero-posterior (AP) ve Skapula-Y grafileri altta yatan patolojileri göstermek için yardımcıdır. Glenoid pozisyonuna göre akromionun lateral örtünmesini ölçen kritik omuz açısı (critical shoulder angle, CSA) ve akromiohumeral indeks (AI) omuz AP grafisinde ölçülebilir. Kritik omuz açısının $35^{\circ}$ üzerinde olması rotator manşet patolojisinin subakromial sıkışmaya eşlik ettiğini düşündürür. Benzer şekilde akromiohumeral mesafe (acromiohumeral distance, AHD) rotator manşet patolojileri hakkında fikir verir. Akromionun inferior kenarından humerus başına ölçülen bu mesafe normalde erkeklerde 7-14 mm, kadınlarda 7-12 mm'dir. Omzun $20^{\circ}$ kaudo-kranyal açı ile çekilen gerçek AP grafisinde (Zanca grafisi) akromioklaviküler eklem ve patolojiler daha detaylı görülür. Skapula Y grafisi humerus başını ve glenoid patolojileri görmek için faydalıdır. Akromion tipini en iyi gösteren grafi ise outlet görüntülemedir. ${ }^{[9]}$

Diğer görüntüleme yöntemleri arasında manyetik rezonans görüntüleme (MRG) ve ultrason sayılabilir. Altı haftalık tedaviye rağmen yanıt alınamayan hastalar için MRG önerilir ve kemik ile yumuşak doku yapılarının daha iyi görüntülenmesi sağlanır. ${ }^{[11]}$ Ultrasonun kullanım alanı kısıtlı olsa da bursit, tendinopati ve tendon rüptür tanıları için yardımcı olduğu bildirilmiştir. ${ }^{[12]}$ 


\section{Tedavi ve Prognoz}

Omuz sıkışma sendromunun klasik tedavisinde konservatif tedaviler önde gelmektedir. Fizyoterapi, non-steroid antienflamatuvar ilaçlar (NSAi) ve subakromial enjeksiyonlar en çok uygulanan yöntemlerdendir. Diğer konservatif tedavi seçenekleri içerisinde hipertermi, ultrason, ekstrakorporeal şok dalga terapisi (ESWT), lazer, akupunktur ve düşük frekanslı elektromanyetik alan uygulaması sayılabilir ve bu yöntemler için düşük kanıtlarla sonuçlar bildirilmiştir. Cerrahi dışı tedavi yöntemlerinin ilk 3-6 ay arasında başarısız kaldığı ya da altta yatan yapısal bir sebep gösterildiği durumlarda cerrahi tedaviler tercih edilmektedir. Günümüze kadar yapılan çalışmalarda cerrahi yöntemlerin konservatif yöntemlere göre ağrı, fonksiyon ya da prognostik açıdan daha üstün olduğunu bildiren yayınlar bulunsa da yüksek kanıt düzeyinde gösterilmemiştir.

\section{Konservatif yöntemler}

Konservatif tedavi yöntemleri içerisinde en önde gelen fizyoterapi egzersizleridir. Uzman eşliğinde düşük rezistanslı egzersizler eklem ve yumuşak dokuların mobilizasyonunu hedefler. Sarkaç hareketleri, esnetme ve kuvvetlendirme egzersizleri ev hareketleri şeklinde günde iki kez beşer dakika uygulamanın etkinliği gösterilmiştir. Egzersiz tedavisinin diğer tüm konservatif yöntemlere ve kontrol grubuna göre ağrı ve Constant skorları bakımından kısa ve orta dönemde üstünlüğü birçok randomize kontrollü çalışma ile gösterilmiştir. ${ }^{[13]}$ Giombini ve ark. hipertermi makinesiyle uygulanan terapinin $(434 \mathrm{MHz}$, $30 \mathrm{dk}$, haftada üç kez, bir ay boyunca), altıncı haftada Constant skoru ve ağrı için egzersize üstün olduğunu bildirmişlerdir. ${ }^{[14]}$ Ultrason tedavisi için $\left(1 \mathrm{MHz}, 2\right.$ watt $/ \mathrm{cm}^{2}$, haftada üç), yapılan birçok çalışmada plasebo ya da diğer yöntemlere karşı herhangi bir üstünlük belirtilmemiştir. ${ }^{[15]}$ Güncel olarak Alfredo ve ark., lazer tedavisinin kısa dönem sonuçlarında etkin olduğunu gösteren 120 hastalık randomize kontrollü çalışmalarını bildirmişlerdir. ${ }^{[16]}$ Akupunktur tedavisi ve düşük frekanslı elektromanyetik alan tedavisi hakkında çelişkili sonuçlar veren yayınlar bulunmaktadır. ${ }^{[17-19]}$

\section{Subakromial enjeksiyon}

Kortikosteroid enjeksiyon uygulaması ile ilgili birden fazla tanımlanmış metot olmakla birlikte en çok kullanılan yöntem 21 gauge enjektör ile posterior subakromial yaklaşımdır. ${ }^{[20]} \mathrm{Bu}$ yaklaşımda akromionun posterior köşesinden $1 \mathrm{~cm}$ medial ve inferiorda bulunan posterior omuz portalı kullanılır ve antero-superior yönde iğne ilerletilir. Enjeksiyon sırasında direnç olmamalıdır. Direnç varlığı iğne ucunun rotator manşet içerisinde olduğunu düşündürür ve yönelim hafif inferiora alınır. $40 \mathrm{mg}$ triamsinolon veya metilprednizolon ile $2 \mathrm{ml}$ lokal anestezik uygulamasının dört hafta sonunda semptomların gerilemesi üzerine olumlu etkisi olduğu ve ultrason eşliğinde yapılan enjeksiyonların daha etkili olduğu gösterilmiştir. [21]

\section{Cerrahi tedaviler}

Omuz sıkışma sendromu olan hastaların yaklaşık \%30'u için cerrahi tedavi uygulanmaktadır. ${ }^{[22]}$ Üç-altı aylık süre içerisinde konservatif tedavinin başarısız olması cerrahi endikasyondur. Taheriazam ve ark., konservatif tedavinin başarısız olacağını ön görebilecekleri faktörleri ortaya koymaya çalışmışlardır. Bu çalışmaya göre başlangıç Constant skorunun daha yüksek olması, semptomların daha uzun süredir varlığı ve tip 2 ya da tip 3 akromion morfolojisi varlığı hastanın daha yüksek oranla cerrahi ihtiyacı olacağını göstermektedir. ${ }^{[23]}$ Uygulanan cerrahi işlemler için subakromial dekompresyon, bursektomi, açık veya artroskopik uygulanan akromioplasti, korakoakromial ligaman eksizyonu, koplaning, distal klavikula rezeksiyonu ve eşlik eden rotator manşet tamiri sayılmaktadır.

Neer 1972'de kronik sıkışma sendromu olan hastaların antero-lateral insizyon kullanarak ve deltoidin akromiondan kısmen kaldırıldığı açık akromioplasti yöntemiyle akromionun anterior inferior kısmının korakoakromial ligaman ile çıkartılmasını tariflenmiştir. ${ }^{[4]}$ Artroskopik tekniklerin ilerlemesiyle bu işlem artroskopik olarak uygulanmaya başlamış ve 1987 'de Ellman artroskopik subakromial dekompresyon (ASAD) cerrahisini ik kez tanımlamıştır. ${ }^{[24]}$ Artroskopik subakromial dekompresyon bu tarihten itibaren rotator manşet patolojilerinde standart prosedür haline gelmiştir (Şekil 1-3). Artroskopik dekompresyon tekniğiyle iyi ile çok iyi arasında sonuçlar bildiren yayınlar mevcut olmakla birlikte Dong ve ark.'nın yaptığı meta-analize göre artroskopik yöntem açık cerrahiye göre erken dönem avantajlar sağlasa da bir yıllık sonuçlar açısından fark göstermemektedir. ${ }^{[25]}$ Artroskopik yöntemin erken dönem avantajları için daha kısa hastane yatışı, günlük yaşam ve aktivitelere daha hızlı dönüş öne çıkmaktadır.

\section{Subakromial dekompresyon}

Subakromial mesafenin arttrılmasını ve patolojik dokuların uzaklaştııımasını hedefler. Açık ya da artroskopik cerrahi olarak uygulanabilir. Dekompresyonun artroskopik olarak uygulanmasının avantajları literatürde geniş yer bulmuştur. Artroskopik olarak uygulandığında 


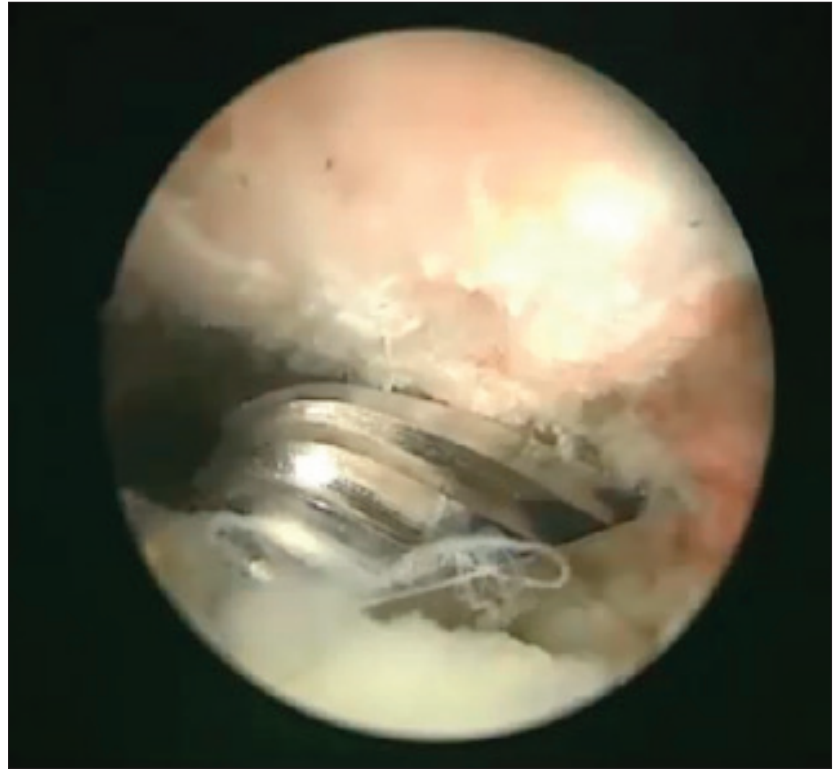

Şekil 1. Akromial spurun eksizyon öncesi görüntüsü.

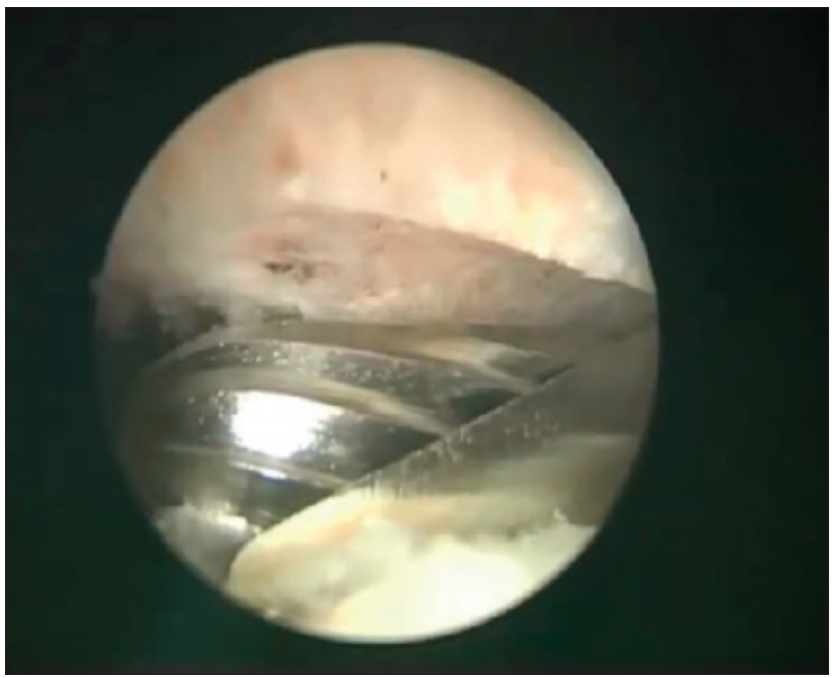

Şekil 2. Akromionizer ile cutting block tekniğine uygun olarak akromionda yer açılması.

standart posterior portal kullanılarak yapılan diagnostik görüntüleme sonrası lateral portal yardımıyla subakromial boşluğa müdahale etmek mümkündür. Bu aşamada bursektomi tek başına yapılabileceği gibi korakoakromial bağ gevşetilmesi ya da eksizyonu, akromioplasti ile birlikte de yapılabilir.

\section{Bursektomi}

Posterior portalden girilen trokar ile öncelikle bursal yapışıklıkların açılması sağlanır. Lateral portalden kullanılacak olan bir shaver yardımıyla subakromial bursa temizlenerek genişletilir. Medialde kanlanması daha fazla olan

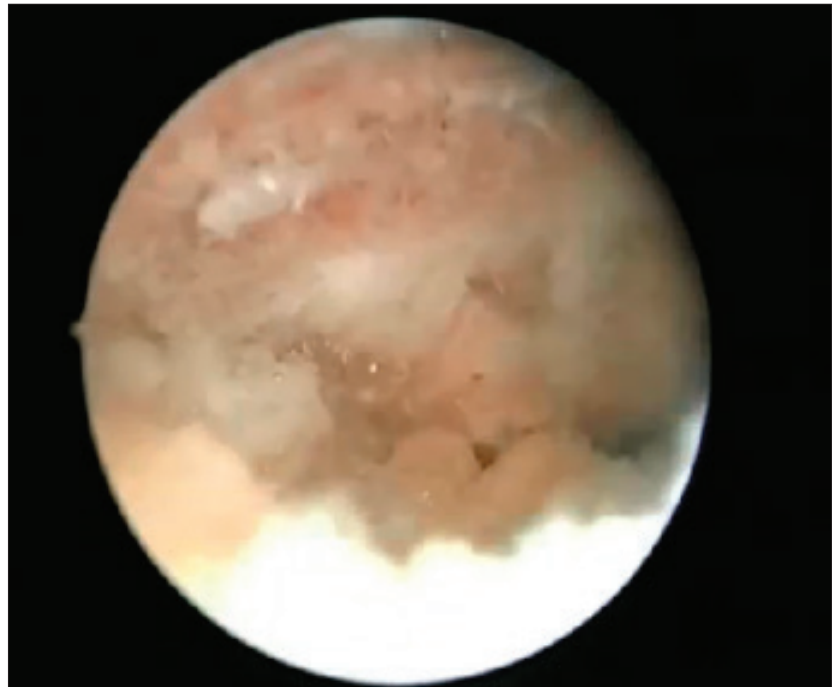

Şekil 3. Dekompresyon sonrası akromionun artroskopik görüntüsü.

dokular görüntüyü bozacağı için bursektomi en lateralden başlanarak kontrollü olarak mediale doğru devam ettirilir. Bursektominin akromioplasti olmaksızın tek başına yapılmasının yeterli olduğunu savunan yazarlar da mevcuttur. Donigan ve Wolf yaptıkları sistematik incelemede, izole bursektomi uygulamak ile bursektomi ve akromioplastiyi birlikte uygulamanın uzun dönem sonuçlar için istatistiksel fark göstermediğini savunmuşlardır. ${ }^{[26]}$

\section{Korakoakromial ligaman eksizyonu}

Korakoakromial ligamanın akromial tarafı üzerinde dejenerasyon bulgularının görülmesinin subakromial sıkışma ve rotator manşetin bursal yüzey yırtıklarıyla ilişkisi belirtilmiştir. Belirgin saçaklanma olduğu durumlarda bu ligamanın gevşetilmesi ya da eksizyonu önerilir. Standart lateral portalden bursektomi yapılmasını takiben akromion ve korakoakromial ligamanın akromial yapışma yeri görülür hale getirilir ve radyofrekans ablasyon probu yardımıyla rezeksiyon sağlanabilir.

\section{Artroskopik anterior akromioplasti}

İki şekilde yapılabilir. ilk olarak kameranın lateral portale taşınması ile posterior portalden burr yardımıyla cutting block tekniği akromionun posterior köşesi referans alınarak anteriora doğru akromionun eksizyonudur. İkinci teknik (kameranın posterior portalde kalması) alışık olunan görüntü sebebiyle daha çok tercih edilir. Lateral portalden burr kalınlığı referans alınarak ( 5-6 $\mathrm{mm}$ ) anterior akromioplastiyi tamamlamak mümkündür. Akromioplasti sırasında kanama olabileceği unutulmamalıdır. Anteriorda deltoid kasının lifleri göründüğü yer durma noktasıdır. 6-8 mm'den fazla eksizyon yapılması akromion kırık riskini arttıracağı için önerilmez. 


\section{Lateral akromioplasti}

Geniş lateral akromionun rotator manşet yırtığına sebep olabileceği düşüncesiyle yapılması önerilmiştir. Artroskopik olarak uygulamak mümkün fakat rutin uygulanmasının ve sonuçlarının subakromial sıkışma tedavisindeki başarısı hakkında literatürde yeterli veri yoktur.

\section{Eş düzlemleme (Coplaning)}

Coplaning, akromioklavikular ligaman eksizyonu olmaksızın inferior akromial osteofitlerin ve klavikulanın lateral son kısmının eksizyonunu ifade etmektedir. $\mathrm{Bu}$ yolla rotator manşet zedelenmesinin önüne geçmek hedeflenir (Şekil 4). Akromioklaviküler eklem ilişkili semptomlara yol açabilmesi nedeniyle bu yöntemin uygulanması ve sonuçları tartışmalıdır. ${ }^{[27]}$

\section{Distal klavikula eksizyonu}

Akromioklavikuler eklem patolojisine bağlı şikâyet fazla ise uygulanabilir. Standart anterior portal yardımıyla klavikulanın artroskopik burr ile distal $5 \mathrm{~mm}$ tam kat rezeksiyonu yeterli dekompresyon sağlamaktadır. Rezeksiyon sırasında akromioklavikuler ligamana ek patoloji oluşturmamak için dikkat edilmelidir.

Artroskopik subakromial dekompresyon cerrahisinin iyi sonuçlarına rağmen yaklaşık \%10-12 hastanın ameliyat sonrası ağrı ve fonksiyon kaybının devam ettiği dikkat çekmektedir. Singh ve ark. hastaların hangi özelliklerinin sonuçları etkilediğini araştırmış ve 112 ASAD uygulanan hastanın 3. ve 12. ay sonuçlarını incelemiştir. Bu çalışma cerrahi öncesinde radyolojik olarak sıkışmaya sebep olan patolojinin gösterilebilir olmasının ve hastanın subakromial steroid enjeksiyonuna olumlu yanıt vermesinin iyi cerrahi sonuçlarla uyumlu olduğunu ortaya koymuştur.

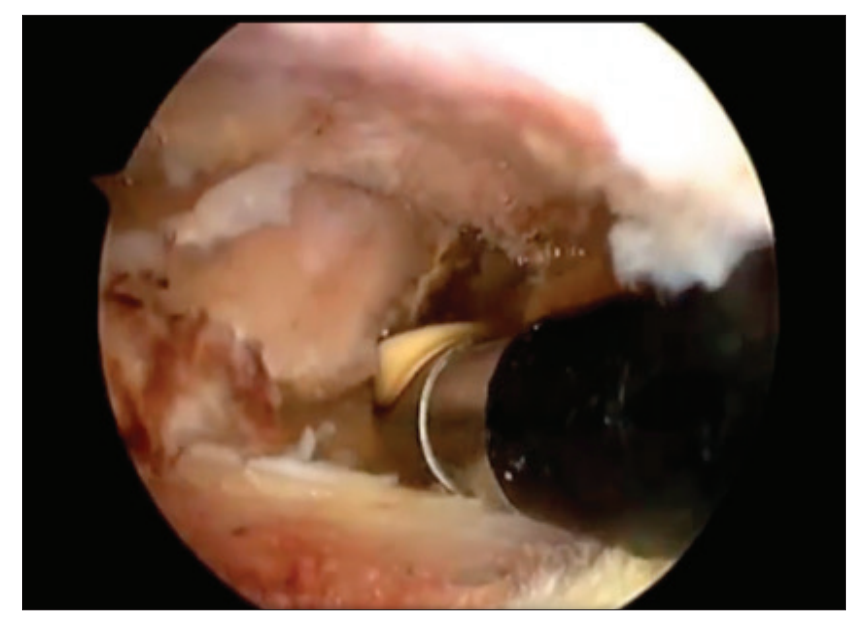

Şekil 4. Coplaning öncesi klavikulanın akromionla aynı seviyede olmadığını gösteren görüntü.
[28] Bir diğer çalışmada, sıkışma sendromuna parsiyel rotator manşet yırtığının eşlik ettiği 62 omzun akromioplasti olmaksızın yapılan artroskopik debridman ile uzun dönem (9,5 yıl) sonuçları \%79 oranında "çok iyi" olarak bildirilmiştir. ${ }^{[29]}$

Yanlış tanı, yanlış endikasyon ya da teknik hataların, tedaviye rağmen hastanın ağrı ve fonksiyon kaybı şikâyetlerinin devam etmesine en çok yol açan sebepler olduğu akılda tutulmalıdır. Tedavisiz kalan bir rotator manşet yırtığının eşlik etmesi, devam eden bir akromioklavikuler eklem enflamasyonu ya da biseps tendinitinin fark edilmemesi başarısız sonuçlara yol açar. Donuk omuz (adhesiv kapsülit), enfeksiyonlar \%0,5'in altında bildirilmiş diğer komplikasyonlar olarak sayılabilir. ${ }^{[30]}$

\section{KAYNAKLAR}

1. Nazari G, MacDermid JC, Bryant D, Athwal GS. The effectiveness of surgical vs conservative interventions on pain and function in patients with shoulder impingement syndrome. A systematic review and meta-analysis. PLoS One 2019;14(5):e0216961. Crossref

2. Consigliere $P$, Haddo $O$, Levy $O$, Sforza G. Subacromial impingement syndrome: management challenges. Orthop Res Rev 2018;10:83-91. Crossref

3. Andersson GBJ, Bouchard J, Bozic KJ. Health care utilization and economic cost of musculoskeletal diseases. The Burden of Musculoskeletal Diseases. Rosemont. IL: Bone and Joint Decade 2008;195-225.

4. Neer $\mathrm{CS} 2^{\text {nd }}$. Anterior acromioplasty for the chronic impingement syndrome in the shoulder: a preliminary report. J Bone Joint Surg Am 1972;54(1):41-50. Crossref

5. Creech JA, Silver S. Shoulder Impingement Syndrome. In: StatPearls. Treasure Island (FL): StatPearls Publishing; July 26, 2021.

6. Kim JM, Kim YW, Kim HS, Lee SC, Chun YM, Joo SH, et al. The relationship between rotator cuff tear and four acromion types: cross-sectional study based on shoulder magnetic resonance imaging in 227 patients. Acta Radiol 2019;60(5):608-14. Crossref

7. Maruvada S, Madrazo-Ibarra A, Varacallo M. Anatomy, Rotator Cuff. In: StatPearls. Treasure Island (FL): StatPearls Publishing; May 8, 2021.

8. Tsai YH, Huang TJ, Hsu WH, et al. Detection of subacromial bursa thickening by sonography in shoulder impingement syndrome. Chang Gung Med J 2007;30(2):135-41.

9. Kloth JK, Zeifang F, Weber MA. Klinische oder radiologische Diagnose des impingements [Clinical or radiological diagnosis of impingement]. Radiologe 2015;55(3):203-10. Crossref

10. Hawkins RJ, McCormack RG. Posterior shoulder instability. Orthopedics 1988;11(1):101-7. Crossref

11. Jaggi A, Lambert S. Rehabilitation for shoulder instability. Br J Sports Med. 2010;44(5):333-40. Crossref 
12. Kadi R, Milants A, Shahabpour M. Shoulder anatomy and normal variants. J Belg Soc Radiol 2017;101(Suppl 2):3. Crossref

13. Gebremariam L, Hay EM, van der Sande R, Rinkel WD, Koes BW, Huisstede BM. Subacromial impingement syndrome--effectiveness of physiotherapy and manual therapy. $\mathrm{Br} \mathrm{J}$ Sports Med 2014;48(16):1202-8. Crossref

14. Giombini A, Di Cesare A, Safran MR, Ciatti R, Maffulli N. Shortterm effectiveness of hyperthermia for supraspinatus tendinopathy in athletes: a short-term randomized controlled study. Am J Sports Med 2006;34(8):1247-53. Crossref

15. Green S, Buchbinder R, Hetrick S. Physiotherapy interventions for shoulder pain. Cochrane Database Syst Rev 2003;(2):CD004258. Crossref

16. Alfredo PP, Bjordal JM, Junior WS, Marques AP, Casarotto RA. Efficacy of low-level laser therapy combined with exercise for subacromial impingement syndrome: A randomised controlled trial. Clin Rehabil 2021;35(6):851-60. Crossref

17. Park JE, Kim WY, Lee SJ, Oh DY, Lee MC, Jeon MK, Nam HJ. Acupuncture treatment for shoulder impingement syndrome: a review of randomized controlled trials. Journal of Acupuncture Research 2021;38(3):175-82. Crossref

18. Paolucci T, Pezzi L, Centra AM, Giannandrea N, Bellomo RG, Saggini R. Electromagnetic field therapy: a rehabilitative perspective in the management of musculoskeletal pain - a systematic review. J Pain Res 2020;13:1385-400. Crossref

19. Hu H, Yang W, Zeng Q, Chen W, Zhu Y, Liu W, et al. Promising application of pulsed electromagnetic fields (PEMFs) in musculoskeletal disorders. Biomed Pharmacother 2020;131:110767. crossref

20. Shang X, Zhang Z, Pan X, Li J, Li Q. Intra-articular versus subacromial corticosteroid injection for the treatment of adhesive capsulitis: a meta-analysis and systematic review. Biomed Res Int 2019;2019:1274790. Crossref

21. Daniels EW, Cole D, Jacobs B, Phillips SF. Existing evidence on ultrasound-guided injections in sports medicine. Orthop J Sports Med 2018;6(2):2325967118756576. Published 2018 Feb 22. Crossref
22. Khan M, Alolabi B, Horner N, Bedi A, Ayeni OR, Bhandari M. Surgery for shoulder impingement: a systematic review and meta-analysis of controlled clinical trials. CMAJ Open 2019;7(1):E149-E158. Crossref

23. Taheriazam A, Sadatsafavi M, Moayyeri A. Outcome predictors in nonoperative management of newly diagnosed subacromial impingement syndrome: a longitudinal study. MedGenMed 2005;7(1):63.

24. Ellman H. Arthroscopic subacromial decompression: analysis of one- to three-year results. Arthroscopy 1987;3(3):173-81. Crossref

25. Dong W, Goost H, Lin XB, Burger C, Paul C, Wang Z-L, et al. Treatments for shoulder impingement syndrome: a PRISMA systematic review and network meta-analysis [published correction appears in Medicine (Baltimore). 2016;95(23):e96d5]. Medicine (Baltimore) 2015;94(10):e510. Crossref

26. Donigan JA, Wolf BR. Arthroscopic subacromial decompression: acromioplasty versus bursectomy alone--does it really matter? A systematic review. lowa Orthop J 2011;31:121-6.

27. Aydın N, Kocaoğlu B, Sarıoğlu E, Tok O, Güven O. The comparison of arthroscopic acromioplasty with and without acromioclavicular coplaning. Ulus Travma Acil Cerrahi Derg 2018;24(3):274-7. Crossref

28. Singh HP, Mehta SS, Pandey R. A preoperative scoring system to select patients for arthroscopic subacromial decompression. J Shoulder Elbow Surg 2014;23(9):1251-6. Crossref

29. Budoff JE, Rodin D, Ochiai D, Nirschl RP. Arthroscopic rotator cuff debridement without decompression for the treatment of tendinosis. Arthroscopy 2005;21(9):1081-9. Crossref

30. Garving C, Jakob S, Bauer I, Nadjar R, Brunner UH. Impingement syndrome of the shoulder. Dtsch Arztebl Int 2017;114(45):76576. Crossref 